\title{
ARTICLES
}

\section{Fiscal policy, public sector management and the 1989 health sector strike}

\author{
Pat Walsh* and Geoff Fougere ${ }^{\dagger}$
}

This paper argues that the 1989 health sector strike grew out of the combined effects of the Labour Government's fiscal policies and its new approach to public sector management. These policies gave rise to a new and not well understood political and industrial environment which held unexpected hazards for all parties. The course and outcomes of the dispute were not under the control of any party, all of whom learnt, as they went along, what the new industrial and political environment held for them.

On February 14, 1989 New Zealand experienced a major, national strike in the health sector. It was the first time that coordinated strike action had been taken on a national basis involving the bulk of workers and a joint campaign by the major health unions. 1 In this paper, we offer an explanation of why the strike took place by placing it in the context of new patterns of public sector management and industrial relations. These patterns are not unique to health, but exemplify in many ways emerging developments throughout the state sector.

The health sector strike, we will argue, resulted from the combined impact of current policy developments in fiscal and public sector management. The choice of a particular model of public sector management - exemplified by but not confined to the State Sector Act and associated legislation such as the Area Health Board Amendment Act and the Hospitals Amendment Act - was in part shaped by the Government's fiscal strategy. This

The order of authorship was determined by flipping a coin. We would like to thank the many people in both unions and management, and elsewhere, who have assisted us in our research for this paper, and those who commented on an earlier draft.

1 In this paper we deal only with the Public Service Association, the Service Workers Federation and the New Zealand Nurses Association. While unions representing local authority employees joined the union campaign part way through and unions representing trades groups also had some involvement, we have focussed our attention on the three major unions only. 
legislation in turn reordered the distribution of resources within health sector industrial relations. In particular, it shaped the parties' definition of their interests, their choice of objectives and the strategios they adopted. In 1988/89 unions and employers faced a new objectives and the strater whe parties learnt what it offered and what it ruled out. The outcomes were certainly not those intended by the architects of the State Sector Act. The Act was conceived as an empowering agent for management. It was this, but in other unexpected and unintended ways it also empowered unions and hobbled management. This latter development revealed itself through the events of the health sector strike. ${ }^{2}$

\section{Fiscal policy}

By 1987 fiscal policy had become a central policy concern. There were at least three major, related reasons for this. The first was nil growth and lower rates of nominal wage increases, both products of Government policy, which meant the increasing tax revenue from rising GDP and fiscal drag that it had inherited from its predecessor were no longer available. Secondly, the Government had almost exhausted its opportunities to restructure the tax system so as to increase overall tax take. Thirdly, these constraints on raising revenue led to a fierce battle within the Government over expenditure. The issuc became defined as a key test of government credibility by the newly powerful financial sector, farmers and some sectors of big business.

These urgent fiscal concerns converged with the Government's wider policies in state sector management. The result was that on December 10, 1987, the Government introduced the State Sector Bill into Parliament and a week later issued the now notorious December 17 tax package. Although particular details of the December 17 package were later spectacularly repudiated by the Prime Minister, its major emphasis upon fiscal restraint was preserved in the 1988 Budget. For our purposes, the Budget's key provisions were:

a) Departments had to absorb a third of the cost of the 1987 wage round and any additional wage-related costs in the 1988 financial year. As the Minister of Finance noted, this required a department wishing to increase its spending on staff to find equivalent savings elsewhere in its budget

b) Departments were required to absorb virtually all price increases relating to their operating expenses.

c) Departments were required to live within their budgets and not to expect supplementary allocations later in the financial year. Any new operational policies were to be funded within the main estimates allocation.

In the past the Department of Health had sheltered boards from periodic budget constraints imposed by central government by making adjustments to its own operations. On this occasion the amount was simply too large. Four months into the financial year Hospital and Area Health Boards were told that their allocations would be three percent less than they had budgeted for. This meant that the full cost of any pay increases,

2 The approach taken here reflects our preference for institutionalist theorising (Ikenberry, 1988; March and Olsen, 1984; Krasner, 1988). In this view, outcomes are seen as resulting from the interaction of strategic choices made by participants with institutional structures. The interests and objectives of the participants and the strategic choices they make are constrained by the resources allocated and the range of options made possible by existing institutional arrangements. Outcomes are no controlled by any one participant, but are shaped by the particular mix of strategy and structure that prevails. We have previously applied a similar theoretical approach to other aspects of industrial relations in New Zealand (Walsh and Fougere, 1987; Walsh, 1989). previously funded by additional funds from central government, would have to be met from within the boards' own current allocations. Boards had had no warning that this level of restraint would be imposed upon them. To their consternation, managers faced a pay round with apparently no money to put on the table.

\section{Public sector management}

The provisions of the State Sector Act were crucial to implementing these policies of fiscal restraint. Prior to the Act, funding of pay increases in the health sector was guaranteed by arrangements known as stabilisation, under which central government reimbursed Boards for wage rises. These wage rises were generated in a number of ways, none of which the Government fully controlled. Most workers in health, as throughout the state sector, received their annual wage increase through the Annual General Adjustment (AGA). This was an estimate of the average private sector wage increase based upon data from the Department of Labour's Quarterly Employment Survey. Some workers gained an additional pay increase through an occupational class pay claim. Negotiations over these claims could ultimately be resolved by compulsory arbitration by the appropriate tribunal. Yet other groups in health relied upon a state linkage clause by which they also received the AGA. Since 1985, most of those workers had discarded their state linkage clause and negotiated awards and agreements under the Labour Relations Act. Ironically, the tight linkage between private and state sector pay and the availability of compulsory arbitration meant that the Government's most effective means of controlling state pay increases operated through whatever influence it could bring to bear upon private sector outcomes.

These pay-fixing arrangements ensured that only infrequently were pay increases related to the specific circumstances of the health sector. A similar situation applied with regard to the negotiation of conditions of employment. These were settled in what were called block negotiations covering the whole state sector. It was also possible for specific issues to be dealt with by way of administrative agreements. However, the bulk of employment conditions in health were settled by a process external to the health sector.

The State Sector Act had dual policy objectives. On the one hand, it was intended to improve the effectiveness and efficiency of the core state sector and thus help the Government realise its public sector management policy objectives. On the other hand, the Act was intended as an instrument of fiscal management. It abolished the AGA and compulsory arbitration and eliminated block service-wide negotiations on conditions of employment. All workers were now required to negotiate pay and conditions in direct bargaining with employers. This made 'hard budgets' possible for the first time in the state sector. Previously, a government bent on fiscal restraint could find its policy undone by the AGA's transfer of large private sector pay increases to state employees, or by a Tribunal ordering a substantial increase for an occupational class. (The Higher Salaries Commission's determination in 1985 was for the Government an egregious example of this and obviously a catalyst for the State Sector Act.) Funding levels were a consequence of decisions already made about pay increases rather than shaping those decisions. Now, the negotiating parameters could be set by prior Government budgetary decisions

The pay round

Hard budgets set limits to industrial strategies in the health sector. Because the amounts available for managers and unions to bargain over were now limited by the prior budgetary decisions of central government, political strategies were now even more 
important than previously as a supplement to industrial strategies for both unions and employers. If more was to be gained by the unions, the government's spendin constraint on the health sector would have to be While the State Sector Act was designed to remove government from the negotiating process, its attempts to tightly limit outcomes set a premium on attempts to shift the Government's position.

This point had particular importance in the health sector because of the legacy of the 1985 negotiations. Then, Ministers had involved themselves directly in the negotiations with junior doctors and nurses, reaching agreements which undercut the official positions of their negotiators. In 1988 this encouraged unions to believe that at the last moment Ministers would again intervene to arrange a favourable settlement. For the general managers it opened the unnerving possibility of being undercut by political intervention.

\section{Unions}

On the union side, the State Sector Act was widely interpreted as having weakened their strategic position. The campaign against the legislation had absorbed union energies and resources to a remarkable degree. This campaign had been followed immediately by exhausting transitional negotiations to codify conditions of employment within awards and agreements. Turmoil associated with the wider process of state restructuring which had begun in 1985 continued to preoccupy the PSA. In the health berth the impact of the Hoctor itsels, haskforce Report, chaired by Alc Hospital Taskforce Report, chaired by Alan Gibbs (Gibbs, Fraser and Scott, 1988), fuelled fears of drastic restructuring and accompanying job losses. The Budget cast further
gloom.

Pursuing an industrial strategy under the State Sector Act required that unions effectively mobilise their members. In the health sector, unions' estimates of their ability to do this varied. The Service Workers Federation (SWF), representing predominantly kitchen staff, cleaners and orderlies, were confident that their members would support industrial action. For the Public Service Association (PSA), representing a diverse mix of occupations (for example, psychiatric nurses, social workers, physiotherapists, speech therapists and public health nurses) the picture was more mixed. While some of their members, in particular the psychiatric nurses, could be counted on to support industrial action, there were doubts about the degree of support available from others. The New Zealand Nurses Association (NZNA) were least confident of all. Their members constituted a majority of health sector workers and were likely to bear the brunt of any health sector restructuring. The clash between a professional ethic of responsibility to patients and a union ethic of worker solidarity made their mobilisation problematic.

Unions faced a common environment of budgetary restraint and health sector restructuring as threats to their members' jobs and living standards. The emergence of these pressures prompted union cooperation. The Combined Health Employees Committee (CHEC) had been initially formed in response to the replacement of hospital boards by area health boards. This required joint activity by unions, as well as the resolution of coverage problems as former central government employees shifted to the area health boards. As more area health boards were formed, CHEC expanded, and by 1988 it was a national organisation which operated at site and regional levels. By then, budgetary pressures were another important factor in promoting union cooperation. The "Nurses are worth more" campaign of 1985-86 involved considerable public sector union cooperation.

As pressures on the health sector intensified, CHEC became a focal point for a union campaign for the preservation and effective development of the public health system. CHEC's formation and development was an explicit recognition that the future of public health and the jobs and living standards of union members were tightly intertwined.
Their protection required a political strategy, to rally public support and thus put pressure on regional and national government, as much as an industrial one. Unions in Auckland had achieved some measure of political success with their participation in the Community Health Coalition which gained four seats on the Area Health Board in 1986. By 1988-89, however, political activity needed to be as much nationally as regionally focussed. Indeed, unions recognised that their capacity to sustain industrial action in health depended importantly upon public sympathy for the plight of the public health system and, by implication, that of the workers employed there. By the 1988-89 wage round, CHEC had given the different union officials and delegates involved a sense of common called by the Council of Trade Unions (CTU) before the pay round were another forum in which health sector unions were able to focus on common problems.

The union approach to the round was shaped by their recognition of the fact of hard budgets and the certainty of continuing restructuring. Common problems and joint consultation meant considerable overlap among union claims on some issues. However, initial cooperation among the unions was immeasurably less than it would become subsequently. Two issues became paramount as the dispute developed. The first was the pay claim itself which was tilted toward lower paid workers and reflected the unions' understanding that they would not win major pay increases. (The tilt toward lower paid workers was a response to the tax changes of October 1988 which had favoured the higher paid). Secondly, unions sought to ensure that they would have an active role in the workplace. This was in part a response to continued restructuring and to the State Services Commission's (SSC) promotion of a 'management culture' in the state sector. A particular concern for the PSA was the SSC's attempts to remove senior management from the coverage of collective agreements and employ them on individual contracts. The PSA's position was that a weakening of union organisation, such as this would entail, made necessary compensating changes to the role of the union in the workplace. This was expressed in its industrial democracy claims. These were designed to give unions a voice, so far denied them, in decisions on state restructuring. For their part, the SWF, in response to looming restructuring, had been trying unsuccessfully for some time to persuade the Government and the Boards to agree to a proposal to implement joint union/ management effectiveness studies to evaluate hospital operation and identify areas where improvements might be made. For its part, NZNA was less enthusiastic about these issues, but went along with the other two in the interests of the wider union alliance.

\section{Employers}

The Area Health Board Amendment Act, passed as an adjunct to the State Sector Act, reconstituted the employers' side of the bargaining table. The Health Services Personnel Commission, the previous employing authority, had been abolished. The State Services Commission had become the employer party for the negotiation of pay and conditions of employment. The Commission was required to consult with the General Managers of each board (who had also been given new powers and responsibilities by the legislation) and the Director-General of Health, and could, if it chose, delegate its responsibilites to the General Managers. This shared jurisdiction and common interests were given operational form in the regular liaison between the General Managers Industrial Committee and the SSC during the negotiations.

The initial strategy meeting to determine employer response to the union claims was held in Christchurch. It brought together the SSC, general managers, industrial relations specialists from the boards, representatives of the Health Department and the Hospital Boards Association. The meeting was not well attended by general managers themselves. This reflected the enormous number of other tasks, particularly those associated with the shift to area health board status, that faced general managers at the time. 
At the meeting, the general managers were told firmly by central government officials that no more money would be forthcoming from the Government to finance any pay settlement. The employers' meeting was effective in determining a common position that remained unchanged until almost the very end of the negotiations. Arguing that the hard budget constraint meant real pay increases could only be funded by job losses, the employers made a nil pay offer coupled with clawback claims affecting payments for call backs, penal rates for night and holiday work and other matters. They also sought to backs, penal rates for remove senior nurses and senior management from coverage of the collective agreement. The employers' claims were as important for what they omitted as for what they included. Employers were aware of the SWF's enthusiasm for effectiveness studies and considered paper at the Christchurch meeting which evaluated their merits, drawing on the Australian experience in Victoria. They concluded that they would not trade off pay increases for the promise of union-management effectiveness studies designed to fund those increases.

While the unions' industrial and political strategies reinforced each other, for the While the credibility of the general managers' industrial strategy depended upon the Government's firm resolve not to provide additional funds, the elected boards had good reason to press the Government for more. Additional funds would placate the unions, ensure the preservation of regional health services and protect their election prospects, all at the expense of central government. So long as boards took this position publicly, unions were encouraged to believe that the industrial position position publicly, unit political strategy was conducted in an unplanned and sporadic way through the appeals of different elected boards for more government funding. Along with the unions' similar attempts, it yielded no success.

The general managers' industrial strategy had much more impact. It mobilised union members and drew the unions more deeply into a joint strategy. The spectre of clawbacks (especially offence sick leave (especially offensi entitlement) on top of a nil pay offer changed the perceptions of many health workers and served as an important organising weapon for unions. Although some differences in
readiness to take direct action remained, the balance had shifted towards militancy.

The conduct of the industrial campaign

Union officials' perceptions were also changed by the employers' strategy and its effect on workers. They faced a common set of claims; they feared a divide and rule strategy by employers trying to settle separately with one union and playing it off against the others; and they were aware that their members were much closer than before in their willingness to take action. This combination added up to pressing reasons for cooperation among unions. Nonetheless, coordinated action was no sure thing.

Divisions abounded within and among the three unions, the PSA, SWF and NZNA state and private sector, white-collar and blue-collar, low-paid and better-paid, industrial and professional orientation. These were reflected in different membership and decisionmaking structures and varied cultures. The PSA and the NZNA were national centralised
unions, whilst the SWF was a federation of autonomous regional unions. Where the SWF and the PSA were coalitions of diverse occupational groups, the NZNA represented a single craft. The SWF was oriented to membership mobilisation and industrial action; waving a professonal oriention and shunned reliance upon A fell in between with sections of its health membership, especially the psychiatric nurses, more akin in their approach to the SWF and others reluctant to take industrial action.

Union officials cooperated in designing a public relations offensive, the 'Squeeze' campaign, aimed to convince their members that they should not be hostages to Governmen 'underfunding' of the public health system. This provided further valuable experience in inter-union cooperation and helped lay the basis for more formal coordination of their overall campaign. By December, the unions had taken the major step of harmonising their claims and had devised a joint campaign which would carry them through to the end of the dispute. This cooperation was premised on inter-union compromises which required continual renewal; consequently its endurance and that of the joint industrial campaign was never guaranteed. Another reason for its fragility was the 'liability of newness'. None of the unions had ever run a joint campaign of this kind before and they learned, sometimes with difficulty, how to do it as they went along.

Cooperation was to occur at the local and regional levels as well as nationally. The campaign had both industrial and political dimensions. Politically, the unions would continue to try to influence public opinion on the need for resources and thus to shift Government. The final aspect of the political strategy was to arrange meetings with Ministers. This was based as much on a need to demonstrate to union members (especially nurses) and to the public that no stone had been left unturned in the union effort to reach a compromise as on any realistic hope of shifting the Government. Industrially, unions built upon their members' anger at the employers' position. The campaign was organised around joint stop-work meetings on January 25 which voted overwhelmingly for a 24 hour strike on February 14 followed by a 48 hour strike on overwhelmingly for a 24 hour strike on February 14 followed by a 48 hour strike on
February 22 , if no settlement had been reached. The length of the proposed strikes was a compromise among the unions, with the SWF firmly supporting more prolonged action.

The Council of Trade Unions played a key role in sustaining the joint union campaign, and later in resolving the dispute. Just as new legislation brought new institutions, and gave rise to novel strategies and possibilities, so too the formation of the CTU in 1988 opened up alternative strategies not previously available to unions. The CTU offered a forum in which unions could temporarily put aside their differences and cooperate. It was a safe place, especially for the PSA and NZNA, still unsure of their ground in the new environment. Its appeal derived heavily from strong relations of personal trust and respect among key union and CTU officials (pointing to the way in elations). Similar cooperation would have CTU, with the SWF affiliated to the Federation of Labour (FOL) and the PSA and NZNA to the Combined State Unions (CSU). Moreover, in the past, state and private sector unions operated under different wage-fixing procedures, making a joint campaign even more difficult. CHEC was an alternative national forum for joint action. Although the SWF might have preferred this, the PSA and NZNA did not. They felt more confident of their capacity to shape events in a CTU forum. What is more, both PSA and NZNA wanted CHEC to become a constituent unit of the CTU and were not about to work through it in preference to CTU structures. Nonetheless, regional and local CHECs played an important role in the coordinated implementation of the national campaign.

The CTU became involved informally in December as the unions began to develop their joint campaign. By January, its participation was formal and continuous, and by they did so under the aut industrial relations staff had anticipated a joint union campaign and CTU involvement, to others it came as a surprise. General mangers were now faced with the need to develop a new strategic response. When this consideration occurred, it revealed divisions among the employers.

These divisions arose from the different impact of strike action on the large, metropolitan boards compared to its impact on small and medium boards. Large boards, much more than the others, had good reason to fear strike action. Their workforces were more committed to union action. Their relationships with their communities were less direct and hence they were less sure they would be able to ensure adequate numbers of volunteers in the event of a strike. The range of services provided by large boards was much greater and the complexity and scale of the tasks required of volunteers meant they were often of little use. They were also responsible for psychiatric hospitals which in 
some cases posed special difficulties for the maintenance of social order. General managers of large boards were also haunted by the possibility of a 'normal accident', by which they did not mean a major disaster but a moderately common event in a large city such as a motorway pile-up. Small and medium-sized boards, on the other hand were generally confident that they could sustain even prolonged strike action. They thought that unions would not be very successful in getting members to strike in their boards. Equally, they were confident that if a strike occurred, volunteers would be able to fill any gaps that appeared. These differences between larger and smaller boards overlapped with others. While health workers in provincial towns may have to put up with whatever wages and conditions they can get, health workers in the main centres may have other the general managers of the large boards, especially after the 24 hour strike, pushed for a settlement, they found themselves opposed by some of the representatives of the smaller boards.

Similarly, the prospect and then the reality of a strike threatened to jeopardise the Government's interests in the dispute. These were essentially three-fold. First, the Government wanted to minimise political damage from the conduct of the dispute. Second it was decrined to preserve its fiscal policy line and not fund a settlement by Sect it was der further budgetary allocations. And, finally, the Government wished to see the new public sector management system it had introduced work and be seen to work well. The Government would achieve this in part by hard budgets and by new management systems. But it also relied heavily upon the central directive role in industrial relations of the SSC as the employer party. Its direction, backed up by a Ministerial sub-committee which monitored developments, allowed the infusion of specific industrial relations expertise and sought to ensure that the Government's immediate interests were protected. For its part, the SSC was conscious that its own role sat uneasily with the decentralised managerialist the SSC was conscious that its own role sat uneasily with the decentralised managerialist
philosophy in the Act. Its future depended upon the Government's continued judgement that a central employer role for the SSC best served Government interests.

The Government's strategy was always high risk. Even as hard budgets seemed to underpin the employers' stance, the Government's political vulnerability threatened the strategy's credibility. The joint union campaign and the 24 hour strike raised the awful possibility of public uproar and of responsibility not just for deficiencies in the health system but for strikes and deaths being sheeted home to the Government. The public system but for strikes and deaths being sheeted home to the Government. The public
would blame unions for deaths seen to arise from the strike action, but they would also certainly blame the Government. Strikes, as we have seen, also carried high risks for al but the general managers of the smaller boards. The Government, and the SSC as its agent, made common cause with the general managers of large boards and looked for a settlement.

Negotiations resumed on a joint basis with all unions sitting together on one side instead of the separate talks the SSC had insisted on until that stage ${ }^{3}$. This allowed negotiations to focus on a general settlement for the health sector. However, the only settlement on offer from the unions included participation by unions in the restructuring process. The shadow of imminent catastrophe in the affairs of the Auckland board had hung over the latter stages of the negotiations. Moreover, all were aware it would be only the first of a series of radical reorganisations. Thus, for the unions, the priority had become effectiveness studies. These appeared inconsistent with the Government's public sector management objectives as set out in the State Sector Act. (However, the Government had also committed itself to industrial democracy, and the Minister of Health had made public statements about the need for union involvement in rationalising the judgements about what constitutes Ministerial direction. health sector.) Not surprisingly, the general managers initially resisted this claim as an unacceptable encroachment upon their managerial prerogatives.

\section{The settlement}

The employers' acceptance of effectiveness studies ensured an overall settlement was reached. The previously contentious issue of pay was resolved fairly easily. The pay settlement fitted into the broad pattern in the state sector of favouring lower paid workers. Employers agreed that no redundancies would occur in the financial year ending June 30 1989 as a direct result of the wage settlement. Boards further agreed they would do their best after June 30 to avoid redundancies as a result of the settlement. Clawbacks were taken off the table. However, many of the matters they raised were consigned to discussion by joint working parties, pointing to their likely return in subsequent rounds. Each union was to return to separate conciliation negotiations to resolve details of thei individual awards. Finally, union pressure for involvement in restructuring was met through a Protocol which comprised four elements. The first was an industrial democracy clause along the lines of those negotiated by the PSA in the public service. The employers accepted the need for employee consultation. Union delegates, who were guaranteed paid time off for this role, were to be the recognised channel of communication. Second, there was an agreement on joint union/managemen effectiveness studies to begin on July 1, 1989. These would review systems and work methods. They were to be preceded by a series of pilot studies whose results were to be available by June 15. The third component of the Protocol concerned the management of change. Employers agreed to involve unions in any reviews which might lead to changes in structure, staffing or work practices affecting employees. The final component was an agreement on staff surplus which provided procedures and options to be followed in the event of redundancies.

The wording of the settlement, particularly the Protocol, leaves it open to diverse interpretations. This wording was not for the most part inadvertent but reflected the urgent need of both sides to reach agreement so as to forestall a second strike. It appears inconsistent with the Government's public sector management objectives but its ambiguity is such that whether this is the case or not will only become clear through the process of implementation. Already significant differences of interpretation have surfaced. Some union officials believe that management can make no changes without extensive union input, while some managers believe that simply notifying the unions that changes will be made is all that is required. Also, the fiscal pressures on boards mean that majo changes are being made, most dramatically in Auckland, under the management of change provisions, separate from the development of effectiveness studies.

The settlement stored up problems but at the same time revealed opportunities for the future. For unions, the pay settlement narrowed pay differentials. If the PSA and NZNA seek to restore those differentials this may make joint membership action with the SWF more difficult. The clawback provisions will undoubtedly return. The unions, like the elected boards, were unable to shift the government on the overall level of health sector funding. On the other hand unions gained experience in working together on an industry basis and despite tensions and difficulties, had enough success to provide incentives to work together in future. This possibility is recognised more formally in current proposals for union reorganization. The legacy of the Protocol remains uncertain. It may be revealed as a document that allowed effective union management cooperation in a time of massive restructuring. On the other hand the danger for unions is that it may turn out to be a means of their cooptation by management. This is possible if union representatives on the studies lack the expertise to play an equal part with management. If the outcomes are seen as those for which management was pressing anyway, but now with union acquiescence, unions may be discredited in the eyes of their members. 
Employers too face a mixed legacy from the settlement. Just as for the unions, if the Protocol is potentially a means for effective workplace cooperation it is also a potential means of cooptation that, in this case, would undermine management discretion. Employers did manage to work together effectively to limit the pay settlement and to get working parties set up on the clawbacks. On the other hand, strike action by the combined unions emphasised differences between larger and smaller boards, making future collaboration more difficult.

For the Government, the settlement preserved their fiscal policy and protected them from direct political damage from health sector upheaval. On the other hand, the goal of management autonomy emphasised by the State Sector Act may have been compromised. The likelihood of strikes in future health sector disputes should also cause disquiet. Governments may not always be so fortunate in enjoying immunity from their consequences.

\section{Conclusions}

The health sector dispute gave rise to events and outcomes not foreseen by any of the participants. What happened was not however simply the result of random accident. Instead the reordering of resources and strategies among participants, a reordering embedded in the procedures of the State Sector Act, explained (but did not determine) particular way in which the process unfolded through the interaction of unions, employers and Government.

Just as the initial differences among unions and their uncertainty about their members' responses explained the lack of uniformity of union claims and their relative modesty, so the initial confidence and unity of employers, and the hard budgets they sought to meet, explained the far reaching scope and the relative uniformity of the claims employers made in uniformity, provided an initial basis for union cooperatio through the growing involvement of the CTU. Union cooperation then opened the way to a widening of union demands for participation in the restructuring process and coupled this with the threat of widespread industrial action. Industrial action acted as a wedge dividing the interests of the Government and large employers, on one side, from those of smaller boards on the other, and greatly increased the pressure on all participants, except bargaining strength, reflected in the final settlement. During the course of the negotiations, the unions' capacity for effective joint action grew while that of employers was to some extent diminished.

The negotiating process also revealed crucial ambiguities in the role of Government. The State Sector Act sought to let governments distance themselves from the state sector industrial relations process, yet allow them tight control over the outcomes. Just as the aims were to some extent contradictory, so too were the outcomes that were generated. Thus the Government's use of hard budgets to strengthen managerial resolve and to limi its expenditure did tightly restrict the outcomes that were possible from the industria negotiations and did so without direct ministerial participation. But the use of hard budgets also led to attempts by elected boards and unions to bring influence to bea directly on the government itself. These attempts were unsuccessful - this time. Their lack of success seems as much to reflect the novelty of the new procedures and the fact that no public catastrophe occurred as a result of strike action, as any enduring feature of the process.

The fragility of the separation of government from the outcomes of industrial bargaining also brought government directly, but covertly, into the industrial negotiating process. (This was formally, but not publicly acknowledged, by Government through the setting up of the ministerial sub-committee to monitor the state pay round, including health. The vicissitudes of the parliamentary life meant that by the end, only one of its original members remained). It is not hard to see why this fragility should be so in the health sector. Once industrial action had occurred, like the large boards and the unions, the Government had good reason to seek a quick settlement (albeit one within its overall fiscal policy). None of them, especially not the Government, were likely to escape blame for any catastrophe that might ensue. The Government was not and could not be indifferent to the need for a settlement and, despite the fictions of the State Sector Act, seems to have instructed the SSC accordingly.

Ambiguities in the State Sector Act were also revealed by the settlement's Protocol, with its emphasis on the role of unions in the management of change in the health sector. The State Sector Act's provisions for increasing managerial autonomy and responsibility, ironically, set in motion a process in which unions came to demand a greater say in management, a demand that potentially undermines the Act's raison d'etre. This is not accidental. Government's tight control of the amount of money available for bargaining focussed the attention of unions and employers on the restructuring of the health sector and inevitably, on union participation in this process.

\section{Postscript}

The events discussed in this paper will not be repeated in the 1989-90 wage round. In October 1989, the major health sector documents were all rolled over, providing for a two percent wage increase, no change in conditions and a shortened term. The documents are due for renewal again in the second half of 1990 . A methodology for effectiveness studies has been agreed to. A union-based effectiveness unit has been set up, funded by the Department of Health.

\section{References}

Gibbs, A, Fraser, D and Scott, J (1988) Unshackling the hospitals: report of the hospitals and related services taskforce Wellington, Government Printer.

Ikenberry, G (1988) Conclusion: an institutional approach to American foreign policy International organization 42(1):220-243.

Krasner, S (1988) Sovereignty: an institutional perspective Comparative political studies 21(1):66-94.

March, J and Olsen, J (1984) The new institutionalism: organizational factors in political life American political science review 78(3):734-749.

Walsh, P (1989) A family fight? Industrial relations reform under the fourth Labour Government. In B Easton (ed) The making of Rogernomics Auckland, Auckland University Press.

Walsh, P and Fougere, G (1987) The unintended consequences of the arbitration system New Zealand journal of industrial relations 12(3):187-198. 


\title{
THE ASSOCIATION OF INDUSTRIAL RELATIONS ACADEMICS OF AUSTRALIA AND NEW ZEALAND
}

\author{
1990 AIRAANZ CONFERENCE
}

\section{CALL FOR PAPERS}

The AIRAANZ Biennial Conference will be held at the University of Melbourne between Wednesday, July 4 and Saturday, July 7, 1990. The Conference Committee is now calling for offers of papers to be presented at this Conference. The general theme of the Conference is current research and teaching in industrial relations.

Offers of papers should be sent to the Conference organiser:

Dr Gerry Griffin

Centre for Industrial Relations and Labour Studies

Department of Economics

University of Melbourne

Parkville, Victoria 3052

Australia

Dr Griffin can be contacted on (03) 344-5306. Closing date for the receipt of offers of papers is February 28, 1990. 